\title{
Select nutrients and glucose transporters in pig uteri and conceptuses
}

\author{
F.W. Bazer', H. Gao', G.A. Johnson², G. Wu' ${ }^{1}$, D.W. Bailey² \\ and R.C. Burghardt ${ }^{2}$
}

Departments of Animal Science' and Veterinary Integrative Biosciences', Texas A\&M University, College Station, Texas 77843-2471, USA

Glucose present in the intrauterine environment can be metabolized, activate cell signaling pathways or be converted to a "storage" form. Total recoverable glucose in uterine fluid of pregnant, but not cyclic pigs increases from Day 12 after onset of estrus in concert with conceptus elongation (Bazer et al. 1991). Transport of glucose into the ovine uterus and its uptake by conceptuses involves sodium-dependent and facilitative glucose transporters (Gao et al. 2009). Glucose can activate FRAP1/mTOR "nutrient sensing" pathway in which protein kinases activate p70S6 through phosphorylation to increase translation of $5^{\prime}$ TOP mRNAs (terminal oligopyrimidine tract) (Wen et al. 2005). Activated FRAP1 also regulates differentiation of trophectoderm (Tr) via Ras transformation by phosphorylating eukaryotic initiation factor 4E binding protein 1 (elF4EBP1), a translational repressor of CAP-dependent translation (De Benedetti \& Rhoads 1990). Select nutrients that stimulate FRAP1 activity in Tr include glucose, arginine (Arg), leucine (Leu) and glutamine (Gln) which may increase expression of ICF2, ODC and NOS mRNAs (Nielsen et al. 1995; Kimball et al. 1999; Martin \& Sutherland 2001) which are required for conceptus development, differentiation and implantation through effects on production of NO (Kaliman et al. 1999) and polyamines (Van Winkle \& Campione 1983). FRAP1 null mice die shortly after implantation due to impaired cell proliferation and hypertrophy in both the embryonic disc and $\operatorname{Tr}$ (Murakami et al. 2004). There are 14 isoforms of facilitative glucose transporters and 6 sodium-dependent glucose transporters. Of these, SLC2A1, SLC5A1 and SLC5A11 mRNAs are most abundant in endometria and SLC2A3 is uniquely expressed by ovine conceptus $\mathrm{Tr}$ and endoderm (Gao et al. 2009). The objective of this study with sexually mature gilts was to identify effects of pregnancy, long-term treatment of ovariectomized gilts with progesterone (P4) and estradiol-induced pseudopregnancy (PP) on changes in amounts of select nutrients (glucose, Arg, Leu and Gln) in uterine fluid and expression of glucose transporters in endometria and conceptuses.

Experiment 1 determined effects of day of the estrous cycle and pregnancy on total recoverable glucose, Arg, Leu and Gln in uterine flushings from gilts on Days 5, 9, 12 and 15 of the estrous cycle $(C y)$ and Days $9,10,12,13,14$ and 15 of pregnancy $(P x)$. Total recoverable glucose, Arg, Leu and $G$ In increased $(P<0.05)$ with day in $C y$ and $P x$ gilts, but only Arg increased more in $P x$ than $C y$ ewes (day $x$ pregnancy status; $P<0.05$ ) between Days 12 and 15.

Experiment 2 determined recoverable amounts of selected nutrients in uterine flushings of gilts ovariectomized on Day 12 and treated daily with either corn oil (OVX-CO;n=4) or $200 \mathrm{mg}$ progesterone (OVX-P4;n - 5) to Day 39 and hysterectomized on Day 40. Values (mean \pm SEM; nmol) were greater for OVX-P4 than OVX-CO gilts for glucose $(4,955 \pm 2,534$ vs $726 \pm 133)$, $\operatorname{Arg}(207,112 \pm 160,979$ vs $7,409+2,877)$ and Leu $(248,255 \pm 178,599$ vs $13,983 \pm 5,225)$, but differences were not significant due to high variability and small sample size.

Experiment 3 determined amounts of selected nutrients in uterine flushings of gilts on Day 90 of pseudopregnancy (PP) induced by treatment with $5 \mathrm{mg} /$ day estradiol benzoate on Days

E-mail: fbazer@cvm.tamu.edu 
11 to 15 after onset of estrus. The flushings $(109 \pm 24 \mathrm{ml}$ ) contained significant amounts (nmol) of glucose $(14,007 \pm 3,946), \operatorname{Arg}(9,051 \pm 1,959), \operatorname{Gln}(4,949 \pm 1,449)$ and Leu $(2,455 \pm 771)$.

Results from examination of uterine and conceptus tissues by in situ hybridization for expression of Facilitative Glucose Transporters SLC2A1, SLC2A2, SLC2A3and SLC2A4 mRNAs indicated that: 1) SLC2A3 mRNA was weak or not detectable in conceptus and uterine tissues; 2) SLC2A1 mRNA was expressed by all cell types in conceptuses and abundant in uterine luminal (LE) epithelium of CY, PX, PP and OVX-P4 gilts; 3) SLC2A4 mRNA was moderately abundant in LE of Px, but not Cy gilts between Days 13 and 25 of Px and by LE and GE of OVX-P4 gilts, but not detectable in LE or GE of PP gilts; 4) SLC2A2 mRNA was most abundant in conceptuses from Days 12 to 40 of Px, decreased to Day 50 and then increased and was maintained specifically in placental areolae and apical regions of interdigitating endometrial folds to Day 80 of Px. SL2CA2 was expressed in uterine LE of Px and PP gilts and LE and GE of OVX-P4 gilts.

Results indicated that: 1) glucose and Arg in particular, but also Leu and Gln, increase in uterine fluids of $\mathrm{Cy}$ and $\mathrm{Px}$ gilts; 2) these select nutrients are abundant in uterine flushings of PP and OVX-P4 gilts; and 3) temporal and cell specific changes occur in expression of specific glucose transporters in the uterus and conceptus. These select nutrients likely stimulate FRAP1 cell signaling in trophectoderm cells of conceptuses to influence proliferation, migration, attachment and gene expression necessary for conceptus development and survival in pigs.

\section{References}

Bazer FW, Thatcher WW, Martinat-Botte F, Terqui $M$, Lacroix MC, Bernard S, Ravault $M$ \& Dubois DH 1991 Composition of uterine flushings from Large White and prolific Chinese Meishan gilts. Reproduction, Fertility \& Development 2 51-59

De Benedetti A \& Rhoads RE 1990 Overexpression of eukaryotic protein synthesis initiation factor 4E in HeLa cells results in aberrant growth and morphology. Proceedings National Academy of Science, USA $878212-8216$

Gao H, Wu G, Spencer TE, Johnson GA, Li X \& Bazer FW 2009 Select nutrients in the ovine uterine lumen: I. Amino acids, glucose and ions in uterine lumenal fluid of cyclic and pregnant ewes. Biology of Reproduction $\mathbf{8 0} 86-93$

Gao H, Wu G, Spencer TE, Johnson GA \& Bazer FW 2009 Select nutrients in the ovine uterine lumen: I1. Glucose transporters in the uterus and periimplantation conceptuses. Biology of Reproduction 80 94-104

Kaliman P, Canicio J, Testar X, Palacin M \& Zorzano A 1999 Insulin-like growth factor-ll, phosphatidylinositol 3-kinase, nuclear factor-B and inducible nitric-oxide synthase define a common myogenic signaling pathway. Journal of Biological Chemistry 274 17437-17444
Kimball SR, Shantz LM, Horetsky RL \& Jefferson LS 1999 Leucine regulates translation of specific mRNAs in L6 myoblasts through mTOR-mediated changes in availability of elF $4 \mathrm{E}$ and phosphorylation of ribosomal protein S6. Journal of Biological Chemistry 274 1 1647-11652

Martin PM \& Sutherland AE 2001 Exogenous amino acids regulate trophectoderm differentiation in the mouse blastocyst through an mTOR-dependent pathway. Developmental Biology 240 182-193

Murakami M, Ichisaka T, Maeda M, Oshiro N, Hara K, Edenhofer F, Kiyama H, Yonezawa K \& Yamanaka S $2004 \mathrm{mTOR}$ is essential for growth and proliferation in early mouse embryos and embryonic stem cells. Molecular Cell Biology $246710-6718$.

Nielsen FC, Ostergaard L, Nielsen I \& Christiansen J 1995 Growth-dependent translation of IGF-II mRNA by a rapamycin-sensitive pathway. Nature 377 358-362

Van Winkle L.J \& Campione AL 1983 Effect of inhibitors of polyamine synthesis on activation of diapausing mouse blastocysts in vitro. Journal of Reproduction and Fertility 68 437-444

Wen HY, Abbasi S, Kellems RE \& Xia Y 2005 mTOR:A placental growth signaling sensor. Placenta 26 S63-S69. 